\title{
PARA EMPEZAR A ENTENDER LA BIOTECNOLOGÍA
}

Jorge Madriz

De acuerdo con lo expresado por el International Food Policy Research Institute (IFPRI), se espera que la población mundial aumente de 8 a 12 billones de personas desde 1995 hasta el año 2020. Cerca del 94\% del incremento de esa población ocurrirá en los países en vías de desarrollo. A lo anterior, hay que añadir, que estas naciones presentan una serie de dificultades socioeconómicas, entre las que se destaca la enorme deuda externa que en 1995 alcanzaba la suma en conjunto de 460 mil millones de dólares (estadounidenses). Lo anterior obliga a los planificadores de políticas económicas y técnicos a buscar soluciones para que, en primera instancia, se favorezca la seguridad alimenticia de tales países y posteriormente, se reduzca la enorme deuda que desvía recursos que podrían utilizarse para solucionar los problemas sociales en cada uno de ellos.

En este contexto, un número significativo de autores sugieren que el uso de la biotecnología en diferentes campos 
de la producción -como la agropecuaria- puede ayudar a resolver el déficit de alimentos que se prevé para el futuro y en consecuencia mejorar la calidad de vida de los habitantes de los países en vías de desarrollo.

Este ensayo expone a un público no especialista en biotecnología, conceptos, definiciones y opiniones de destacados investigadores y pensadores en este campo, que intentarán informar y formar acerca de un tema en el que no existen artículos de fácil comprensión para la ciudadanía, pero que incide directamente en su vida, en el desarrollo de su entorno y plantea nuevos problemas y responsabilidades a toda la humanidad.

Para explicar cómo este conjunto de técnicas puede eventualmente contribuir a la seguridad alimenticia de los países, es necesario comprender qué es la biotecnología, conocer su desarrollo histórico, así como sus aplicaciones y las principales limitantes para su puesta en práctica. Las definiciones sobre biotecnología que a continuación citamos son la base teórica de la práctica cotidiana y todas ellas coinciden en que está conformada por un conjunto de técnicas, que utilizan seres vivos o partes de ellos para obtener un producto:

a) Conjunto de técnicas que permiten la utilización de seres vivos, (microorganismos, células vegetales y animales, etc.) con propósitos industriales y comerciales (Ávalos, 1990).

b) Utilización de organismos vivos o partes de organismos (levaduras, bacterias, células animales y vegetales en cultivo, etc.), para producir o modificar bienes (por ej. vino, cerveza, pan, quesos, antibióticos, vacunas), para mejorar especies vegetales o animales (cultivos alimenticios, industriales, ganado, especies 
de alto valor), o para desarrollar microorganismos para fines específicos (p. ej. antipolutantes) (Brenta, 1997).

c) La biotecnología es la aplicación controlada y deliberada de agentes biológicos sencillos, -células vivas o muertas, o componentes celulares- en operaciones técnicamente beneficiosas, bien sea en la fabricación de productos o como operaciones de servicios (Bu'lock y Kristiansen, 1987).

d) Aplicación de organismos, sistemas y procesos biológicos a la producción de bienes y servicios en beneficio del hombre (Mateo-Box, 1993).

Los procesos donde se utiliza la biotecnología, no son de ninguna manera novedosos: Brenta (1997) indica que las técnicas biotecnológicas más antiguas datan del período Neolítico. Sin embargo, avances recientes registrados en las disciplinas biológicas fundamentales, especialmente en la selección y manipulación del material genético, han aportado el elemento base que ha permitido la implementación y desarrollo de las "nuevas biotecnologías" -por contraposición a las tradicionales-cuyos principales campos son las fermentaciones, las reacciones enzimáticas y la ingeniería genética. Así, una de las diferencias entre las viejas y nuevas biotecnologías radica en el grado en que es posible controlar y dirigir los sistemas biológicos a través de las nuevas tecnologías, entre las que destacan la recombinación del $\mathrm{ADN}$, hibridomas (fusión de un linfocito $\mathrm{B}$ y una célula cancerosa, que tiene la propiedad de crecer indefinidamente, y que se usa para producir anticuerpos específicos) y fermentaciones fundamentalmente. Por ejemplo, la producción de cerveza es una vieja biotecnología, pero si se utilizan levaduras modificadas por recombinación de ADN para mejorar el producto o el proceso, estaremos 
en el campo de las nuevas biotecnologías. Lo mismo ocurre cuando se emplean técnicas clásicas de mejoramiento genético, (por ejemplo en la producción vegetal o animal provocando mutaciones heredables por exposición a radiaciones, por hibridación, etc.) o técnicas nuevas (fusión de protoplastos, recombinación del ADN, etc.).

\section{Ejemplos de la vieja biotecnología}

En 1989, Ward elaboró una excelente reseña histórica de la biotecnología, en la que entre otras cosas indica que esta ha sido utilizada por el hombre desde sus orígenes, apoyándose en varios ejemplos para explicarlo.

Así indica que la fermentación ha sido un arte durante muchos siglos ya que, la elaboración del vino se cree que se practicaba al menos 10.000 años a.C., mientras que los historiadores señalan que los egipcios producían cerveza en los años 5.000-6.000 a.C. dejando germinar la cebada en vasijas de barro y después estrujándola, amasándola y finalmente remojándola con agua para obtener la bebida. Además, hacia el año 4.000 a.C. los egipcios utilizaron las levaduras de la cerveza para la producción de dióxido de carbono para el hinchamiento de la masa del pan. En México, los antiguos aztecas recogían algas del género Spirulina de estanques alcalinos para el consumo alimentario. Los orígenes de una gran variedad de alimentos y salsas fermentadas procedentes del Oriente y de otras partes del mundo, que actualmente se sabe que están basados en procesos de fermentación, producción de enzimas y degradación de productos por medio de la hidrólisis enzimática, se remontan claramente a muchos miles de años. Asimismo, la producción de alimentos y bebidas modificadas mediante procesos de fermentación es conocida desde aproximadamente 10.000 años antes de que se supiera de la existencia 
de microorganismos, siendo también evidente que estas tecnologías tradicionales han ido mejorando gradualmente. El examen microscópico de los sedimentos de las urnas de cerveza excavadas, que datan del 3.400 al 1.440 a.C. demuestra claramente que la mayoría de las veces contienen levaduras, observándose también en los sedimentos más recientes, que la pureza de las levaduras utilizadas es mayor.

Los datos acerca de la transformación de la leche en derivados lácteos, como el queso, se remontan al año 5.000 a.C. cuando las tribus nómadas que utilizaban los estómagos de las terneras como recipientes, observaron que aquella se cuajaba por la acción enzimática.

Otros ejemplos que igualmente ilustran la antigüedad del uso de la biotecnología son el vinagre, que probablemente se conoció desde el momento en que se obtuvo vino, aunque los datos más tempranos referidos a este compuesto se hallan en el antiguo y nuevo testamento, y la destilación del alcohol, ya que las primeras referencias de bebidas obtenidas mediante este proceso datan del año 10.000 a.C. en China.

Desde el punto de vista farmacéutico, los quesos, la carne y el pan enmohecido se han empleado en la medicina popular durante miles de años para curar heridas y tratar las infecciones. Ahora se sabe que los efectos beneficiosos de tales tratamientos se debían indudablemente a la actividad antibiótica de esos mohos u hongos.

Además, cuando Ward (1989), en la reseña histórica que cito, se refiere específicamente a la tecnología microbiana, indica que hubo dos elementos que condicionaron el inicio de la era moderna de la fermentación industrial: el empleo tradicional de mohos y levaduras en la modificación de alimentos y bebidas y los estudios microbiológicos pioneros de científicos como Pasteur y Koch cuyos estudios condujeron al desarrollo y utilización industrial de procesos 
de fermentación đe superficie o semisólidos, la obtención de proteínas microbianas (proteínas de organismos unicelulares) y la producción de ácidos orgánicos entre otros.

\section{Tendencias de la nueva biotecnología}

La nueva biotecnología o biotecnología moderna, corresponde a un conjunto de técnicas, más eficientes que las anteriores, desarrolladas durante las últimas décadas a partir de avances de la biología celular y molecular así como de la enzimología, pero es especialmente el conjunto de técnicas que se desarrollan a finales de los años setenta -fuertemente basadas en los descubrimientos de la genética molecular y de la inmunología- el que origina la denominada nueva biotecnología. Esta última tiene que ver, fundamentalmente, con la recombinación del ADN y la fusión celular, y ha progresado aceleradamente en los últimos años, ampliando en forma notable su campo de aplicaciones (Ávalos 1990).

Este mismo autor, indica que la nueva biotecnología, junto con la informática y la robótica, constituye la tercera gran revolución del siglo XX -y probablemente de buena parte del siglo XXI-, y que todas ellas tienen en común una fuerte base científica y una gran aplicación tecnológica.

La nueva biotecnología comenzó de manera específica, con la manipulación de células mediante técnicas de ácido desoxirribonucleico recombinante (ADNr). Las tecnologías básicas que lo conforman pueden ser clasificadas alrededor de los siguientes grupos:

- Técnicas para el cultivo de células y tejidos.

- Procesos biotecnológicos, fundamentalmente de fermentación, que incluyen las técnicas de inmovilización de enzimas. 
- Técnicas que aplican la microbiología a la selección y el cultivo de células y microorganismos.

- Técnicas para la manipulación, modificación y transferencia de material genético entre individuos de especies distintas (ingeniería genética).

Aún cuando las tres primeras se complementan entre sí, hay una diferencia fundamental entre estas y la cuarta; aquellas se basan en el conocimiento de las características y el comportamiento de los seres vivos y su uso para lograr ciertos objetivos industriales; el último grupo (muchas veces se cree que solo esto es biotecnología) implica no solo el conocimiento, sino la capacidad de manipular los rasgos y el modo de funcionamiento de los organismos, también con propósitos industriales.

Cuando se refiere al campo de la aplicación de la biotecnología, Ávalos (1990) indica que es muy variado y que en lo que concierne a la agricultura, las nuevas biotécnicas permitirán -en particular a través de la manipulación genética y del cultivo de tejidos-, generar variedades de alto rendimiento pero con un consumo mínimo de agroquímicos, y sustituir el patrón tecno-productivo de la "revolución verde", que estaba basado en el uso intensivo de los fertilizantes y de biocidas, muchas veces contaminantes del entorno rural.

Del conjunto de los cuatro grupos de técnicas que conforman la nueva biotecnología mencionadas anteriormente, las tres primeras tienen una amplia aplicación en la agroindustria (recombinación, fermentación e ingeniería enzimática), y la cuarta (el cultivo de células y tejidos para la selección, mejoramiento y reproducción de plantas en el laboratorio), de gran importancia en la agricultura, y por tanto en el circuito agroalimentario y en la producción de materias primas adaptadas a las necesidades de la 
agroindustria. Un buen ejemplo de esto lo constituye la necesidad que tiene la industria procesadora de tomates de trabajar con una materia prima con bajo contenido en agua, ya que esto aumenta su rendimiento y disminuyen los costos del procesamiento. Esto ha llevado a las procesadoras de tomates, a promover la investigación, para obtener, utilizando la recombinación génica y el cultivo de tejidos, variedades de tomate con bajo contenido de agua.

Algunas técnicas ubicadas dentro del cuarto grupo cuya aplicación tienen una mayor posibilidad de éxito en los países en vías de desarrollo son: el mejoramiento de los métodos de diagnóstico de patógenos en la agricultura, el control biológico contra plagas y enfermedades, la producción de plantas resistentes a los virus, la producción de vacunas para animales, el mejoramiento genético por trasplante de embriones y el mapeo genético de plantas y animales dentro de programas de mejoramiento.

Según Sittenfeld et al. (1991), en Costa Rica, los mayores esfuerzos de investigación y desarrollo en biotecnología deben dirigirse hacia los sectores agropecuario, agroindustrial y de salud. En el sector agrícola, las biotecnologías más promisorias son: la multiplicación y regeneración de especies vegetales por medio del cultivo in vitro, el desarrollo a gran escala de metodologías para el diagnóstico de enfermedades y la consecuente producción de variedades libres de ellas. Posteriormente, mediante la ingeniería genética, se podrá llegar a la producción de plantas resistentes o tolerantes a los virus. Otros aspectos importantes son la propagación in vitro de especies forestales dentro de programas de reforestación, el desarrollo de métodos para el control de fitopatógenos mediante el empleo de microorganismos y productos biológicos y la 
optimización de la fijación biológica de nitrógeno atmosférico.

$\mathrm{El}$ autor mencionado indica, además, que un campo importante de desarrollo biotecnológico para el sector agrícola será la caracterización y estimación de la variabilidad genética existente en el germoplasma, tanto mediante los métodos tradicionales de marcadores de isoenzimas, como los más recientes que evalúan el polimorfismo de segmentos de ADN. Además de los métodos de caracterización se deben establecer los bancos de germoplasma respectivos, así como la identificación y enumeración de la diversidad biológica vegetal, dentro de una estrategia de aprovechamiento de la misma, para la generación de nuevas variedades de interés agrícola.

Los ámbitos de aplicación biotecnológica más importantes en el campo pecuario son el desarrollo de métodos de diagnóstico, prevención y control de enfermedades, la búsqueda de nuevas alternativas de bajo costo para mejorar la nutrición animal, la promoción del crecimiento y el mejoramiento genético animal por medio del transplante de embriones.

Sin embargo, a largo plazo los proyectos que podrían ser más promisorios son los relacionados con la utilización de la biodiversidad y su respectiva información genética, condición en la cual Costa Rica posee ventajas geográficas.

\section{Ética en Biotecnología}

Existe un debate en cuanto al rumbo que ha tomado la biotecnología en los países subdesarrollados; algunos autores como Goldstein (1989), señalan que nuestros países deben dedicarse a la biotecnología vegetal, porque, 
principalmente, sus economías son agroexportadoras y añade que "a los planificadores de nuestro desarrollo les interesa sobre todo que aprendamos bien las técnicas de micropropagación y que las apliquemos para mantener buenos bancos genéticos, es decir, que sepamos cuidar bien nuestras reservas útiles, ya que la información genética es un patrimonio de la humanidad toda, y aquellos que tienen la infinita suerte de residir en regiones donde se encuentran los principales reservorios de genes potencialmente útiles del mundo (la mayor variedad de animales, plantas, hongos, virus, bacterias) deben ser capaces de conservarlos para que toda la humanidad pueda utilizarlos libremente".

De acuerdo con ese autor, los países subdesarrollados tienen el compromiso moral de dedicar sus esfuerzos intelectuales y sus recursos financieros a cuidar y conservar el germoplasma, que a su vez debe ser entregado gratuitamente a cualquiera que lo desee. Por otra parte, los países desarrollados tienen el derecho inalienable de tomar la información genética que deseen, reempaquetarla y vendérnosla bien cara en forma de semillas y agentes farmacológicos, junto con toda la parafernalia agregada de la agroindustria. Es decir, nosotros micropropagamos y ellos modifican las plantas a voluntad. Nosotros conservamos el germoplasma y ellos toman los genes que les convienen y los mezclan a voluntad. 
Para recalcar lo anterior, Goldstein presenta el siguiente cuadro:

\section{América Latina Primer Mundo}

Hace plantitas

Estudia la fisiología, la bioquímica, la genética molecular y la patología molecular de las plantas de interés comercial.

Conserva germoplasma

Aísla y clona los genes que codifican proteínas de interés para las industrias agroquímicas, farmacéuticas y alimentarias. Caracteriza las moléculas responsables de acciones farmacológicas de interés y establece las sendas biosintéticas.

Exporta materiales sin procesar

Exporta semillas y plantas o con mínimo valor agregado patentadas,

quimeras genéticas patentadas y productos de alto valor agregado, en muchos casos derivados de germoplasma latinoamericano.

Fuente: Goldstein, D. J. 1989. Biotecnología, Universidad y Política. Siglo Veintiuno Editores. México. 257 pp. 
Independientemente del criterio de los especialistas, es indudable que el uso racional de la tecnología, y en este caso, de la biotecnología, debe ser principalmente en beneficio del ser humano y ambientalmente apropiable, lo cual significa, según Izquierdo et al., (1995) que las "herramientas biotecnológicas que contribuyen al desarrollo sostenible al ser técnicamente factibles dentro del nivel de desarrollo tecnológico de un país; al promover beneficios tangibles a los destinatarios y ser ambientalmente seguras, y socioeconómicamente y culturalmente aceptables...".

Así también el expresidente Jimmy Carter dijo en un discurso: "La biotecnología responsable no es el enemigo; el hambre sí lo es. Sin fuentes de alimentos adecuadas y a precios asequibles, no podemos esperar que haya salud y paz en el mundo".

\section{Glosario}

ADN (ácido desoxirribonucleico): Larga cadena de moléculas presente en la mayoría de las células, que lleva el mensaje genético y controla todas las funciones celulares.

ADNr: ADN producto de la combinación de ADN de diferentes fuentes.

Anticuerpos: Proteína inmunológica, producida por cierto grupo de células blancas del sistema inmune, como respuesta del organismo al contacto con una sustancia extraña (antígeno) al cuerpo.

Biocida: Sustancia que es capaz de acabar o disminuir una forma de vida en particular.

Diversidad genética: Variación genética dentro y entre poblaciones, que es creada, mejorada o mantenida por fuerzas evolutivas.

Embrión: Organismo inmaduro en sus primeros estados de desarrollo. 
Enzima: Proteína producida por las células vivas, que, aún en bajas concentraciones, cataliza reacciones químicas específicas, pero no son usadas en esas reacciones.

Fermentación: Degradación por microorganismos de sustancias complejas como carbohidratos en condiciones anaeróbicas.

Germoplasma: Material genético que forma la base física de la herencia y que se trasmite de una generación a otra. Híbrido: Cruce resultante de dos individuos genéticamente diferentes.

Hibridación: Entrecruzamiento de especies, razas o variedades entre ellas mismas. Proceso de formación de un híbrido por polinización cruzada en plantas o por apareamiento de animales de diferentes tipos.

Hibridoma: Célula híbrida, derivada de un linfocito B (productor de anticuerpos) y una célula tumoral, que crece indefinidamente en un medio de cultivo.

Hidrólisis: Reacción en que una molécula de agua se agrega a un sitio de corte para dar dos productos.

Ingeniería genética: Cambios en la constitución genética de las células, como producto de la introducción o eliminación de genes específicos usando técnicas modernas de biología molecular.

Isoenzimas: Variante de una enzima particular, tiene la misma función y algunas veces la misma actividad, pero difiere en su secuencia de aminoácidos.

In vitro (en vidrio): viviendo en tubos de ensayo, fuera del organismo o en un ambiente artificial.

Levaduras: Hongo Ascomiceto unicelular, comúnmente encontrado como contaminante en cultivo de tejidos vegetales.

Linfocito: Clase general de células blancas de la sangre, que son componentes importantes del sistema inmune de los vertebrados. 
Mapas genéticos: Arreglo lineal de los genes sobre un cromosoma o su localización física.

Mutación: Cambio heredable natural o inducido, como resultado del cambio en la estructura de un gene, un cromosoma o en el número de los cromosomas.

Polimorfismo: La ocurrencia de dos o más alelos de un locus en una población.

Propagación clonal: Propagación asexual de muchas nuevas plantas a partir de un solo individuo.

Proteína: Macromolécula compuesta de una a varios polipéptidos. Cada polipéptido consiste de una cadena de aminoácidos unidos entre sí por enlaces covalentes.

Protoplastos: Célula bacterial o vegetal en la cual la pared celular ha sido removida química o enzimáticamente.

Recombinación: Proceso de entrecruzamiento entre cromátidas hermanas que ocurre durante la meiosis.

Variabilidad: Diferencias entre individuos entre una población o entre poblaciones.

\section{Bibliografía consultada}

Arias Peñate, S. 1990. Biotecnología: amenazas y perspectivas para el desarrollo de América Central. Ed. DEI, San José, Costa Rica. 282 pp.

Ávalos, G. I. 1990. Biotecnología e industria: un ensayo de interpretación teớrica. San José, Costa Rica. Instituto Interamericano de Cooperación para la Agricultura. 72 pp.

Brenta, N. L. 1987. Biotecnología: ¿Nuevo mito post-industrial? David y Goliat (México), 51:26-33.

Bu'lock, J.; Kristiansen, B. 1987. Biotecnología básica. Ed. Acribia, Zaragoza, España. 557 pp. 
Casas, R.; Chauvet, M. 1996. Biotecnología, Agricultura y Ambiente: una recapitulación. Comercio Exterior (México), 46 (10): 835-845.

Goldstein, D. J. 1989. Biotecnología, Universidad y Política. Siglo Veintiuno Editores. México. 257 pp.

Instituto Interamericano de Cooperación para la Agricultura. 1991. Guías para la liberación en el medio ambiente de organismos modificados genéticamente. Ed. IICA, San José, Costa Rica. 145 pp.

Instituto Interamericano de Cooperación para la Agricultura. 1992. La regulación de la biotecnología con énfasis en la liberación al medio ambiente de organismos modificados genéticamente. Editado por Jaffé, W. R. y Zaldívar, M. E. San José, Costa Rica. 294 pp.

Izquierdo, J.; Ciampi, L.; De García, E. 1995. Biotecnología apropiable: racionalidad de su desarrollo y aplicación en América Latina y el Caribe. Organización de las Naciones Unidas para la Agricultura y la Alimentación. Red de Cooperación Técnica en Biotecnología Vegetal. Santiago de Chile. 81 pp.

Jagnow, G.; Dawin, W. 1991. Biotecnología. Introducción con experimentos modelo. Edit. Acribia S.A. Zaragoza, España. 251 pp.

Mateo Box, J. M. 1993. Biotecnología, agricultura y alimentación. Eds. Organización de Cooperación y Desarrollo Económicos (París, Francia) y Mundi-prensa (Madrid, España). 255 pp.

Otero, G. 1991. Biotecnología y Reestructuración Económica Mundial. Información Tecnológica (Chile), 2(2):51-58.

Sittenfeld, A.; Ramírez, P.; Macaya, G. 1991. "La nueva biotecnología y Costa Rica". Ciencia y Tecnología (Costa Rica), 15(1-2):35-50.

UNESCO And The Mendelianum of the Moravian Museum. 1981. From biology to biotechnology: Progress, protagonists and prospects in life science. Edit by Kinnon, C., Kholodilin, A. N. and Orel, V. Brno, Czechoslovakia. 153 pp. 
Ward, O. P. 1989. Biotecnología de la fermentación. Ed. Acribia S.A., Zaragoza, España. 274 pp.

Zaid, A.; Hughes, H. G.; Porceddu, E.; Nicholas, F. W. 1999. Glossary of biotechnology and genetic engineering. FAO Research and Technology Paper 7. Roma, Italia. $250 \mathrm{pp}$. 